\title{
Evaluation of the Attitudes of Users Towards Youth Centers in Turkey
}

\author{
Özlem Yılmaz' ${ }^{1}$, Rüstem Orhan ${ }^{2}$ \\ ${ }^{1}$ Graduate School of Health Sciences, Kırıkkale University, Kırıkkale, Turkey \\ ${ }^{2}$ Faculty of Sport Sciences, Kırıkkale University, Kırıkkale, Turkey \\ Correspondence: Rüstem Orhan, Department of Physical Education and Sport Teaching, Faculty of Sport Sciences, \\ Kırıkkale University, 71450 Yahsihan/Kırıkkale, Turkey.
}

Received: Jan. 10, 2020

doi:10.11114/jets.v8i4.4678
Accepted: Feb.5, $2020 \quad$ Online Published: Feb. 27, 2020

URL: https://doi.org/10.11114/jets.v8i4.4678

\begin{abstract}
This is an assessment of the Youth Centers (YC) of the Ministry of Youth and Sports (MYS) in Turkey. The users evaluated the youth centers considering the physical environments as well as the activities and programs offered by the centers in educational, pedagogical, social, psychological, physiological and relaxing terms. The sample of the study consists of YC users in Diyarbakır, Kırıkkale, Kocaeli, Trabzon, and Van. A total of 561 volunteers, 359 (64\%) of whom were women and 202 (36\%) were men, (mean age 16-19 (38.5\%)) participated in the study voluntarily. In addition to the personal information form, as the data collection tool, a scale designed by the researchers for the measurement of users' attitudes towards youth centers was employed. The scale was developed from the "Leisure Satisfaction Scale (LSS) designed by Beard and Ragheb (1980). When the results regarding the attitudes of users towards YCs were evaluated, the highest mean was found to be in the psychological sub-factor $(\mathrm{x}=3.84 \pm 1.11)$. The results of the T-test analysis showed that male users evaluated the YCs more positively than female users in the physiological sub-factor $(p<0,05)$. ANOVA and Tukey analyses were performed to see whether there were significant differences between the provinces where the research was conducted. The users in Kırıkkale and Kocaeli, in general, have more positive attitudes towards educational, social, relaxing, physiological aspects of the programs and activities and physical environments of the youth centers than those in Van and Trabzon particularly $(\mathrm{p}<0,05)$.
\end{abstract}

Keywords: youth center, physical education, sports, leisure

\section{Introduction}

There are various definitions and age ranges related to the concept of youth. The United Nations General Assembly defined 'youth', as those falling between the ages of 15 and 24 years inclusive (UNESCO, 2014). Yörükoğlu (2007) stated that the youth period, starting with the first puberty signals, covers the ages of 12-21. According to the Turkish Language Association (TDK), the youth is the period of human life between adolescence and middle age (TDK, 2016). According to the National Youth and Sports Policy Document (UGSPB), youth is a concept that must be defined according to time, social structure, socio-economic developments, culture, and traditions. According to the UGSPB, under the conditions of Turkey, the 14-29 age group can be defined as the youth (MYS, 2013). Heaven and Tubridy (2003) stated that the period of life between childhood and adulthood can be described as the youth process.

Turkey has a young population. The total population of Turkey, as of 2018, is over 82 million and the young population (12 million 971 thousand 396) aged 15-24 constitutes 15.8\% of the total population (TurkStat, 2018 (Population by age group and sex, 2018, 2023, 2040, 2060, 2080)). Turkey is followed by Greek Cypriot with $13.2 \%$, Denmark with $12.8 \%$, and Ireland with $12.4 \%$. The ratio of the young population to the total population is calculated as 11.7 percent in France, 10.5 percent in Germany and 9.7 percent in Italy (AA, 2019).

Among the primary responsibilities of the state are to provide scientific and technological opportunities for the young population, to include them in the economy, to raise them as well-educated and healthy individuals and to create environments where they can use their spare time. Especially in the 21st century, encompassing the Information Age, where rapid and continuous developments are taking place in science and technology, education and training should be in every area and process of life.

According to sociologist Dumazedier (1974), leisure has three basic functions expressed as "relaxation", "entertainment" and "development", that is, 3D (delassement, divertissement, developpement). During the time spared for leisure 
activities, individuals should get rid of their tiredness and stress after work by recreation, and develop themselves in terms of thoughts, identity, and personality through social activities free of self-interest (Güçlü, 2013). UNICEF (2011) states that providing young people with opportunities for efficient leisure activities will reduce social, economic and psychological problems in time.

Leisure is important for a person's daily well-being and activities that are freely chosen for this time period provide more opportunities for satisfaction. Thus, the door to a high sense of satisfaction opens up (Broughton \& Beggs, 2006).

Youth Centers are public institutions where lifelong learning takes place and young people can enjoy their free time (Duden, 2016). One important function of youth policy is the youth centers established for young people to provide opportunities for active living and gaining better skills. Youth centers in Turkey conduct activities in painting, music, theater, sports education, folk dances and scouting within the body of provincial directorates under the Ministry of Youth and Sports (Karabulut \& Pulur, 2011). These centers also organize EU projects, domestic mobility and exchange programs, competitions and contests in various fields and carry out social responsibility activities (Baş, 2017).

Youth Centers in Turkey offer workshop activities, club activities, and meeting programs. The workshops provide the education of young people in the fields of language, values, religious sciences, innovation, social sciences and personal development under the name of "Youth Centers Academy". While the clubs organize social and cultural activities in such fields as handicrafts, music, and the environment, young people meet prominent people, writers, and poets who can inspire them through meeting programs (MYS, 2016)

The youth center programs first started in Ankara in 1970 and they have been spread throughout the country since then. While the number of members of the Youth Centers was 11.614 in 2002, with the establishment of the Ministry of Youth and Sports in 2012, it increased rapidly to 1,270,070 in 2015 (MYS, 2016). As of November 2018, the number of Youth Centers reached 285 and the number of the users was 2,027,280 (977,893 males and 1,049,387 females).

\section{Method}

The aim of this study was to investigate the attitudes of YC users towards educational, social, psychological, physiological and relaxing aspects of the activities and programs carried out by youth centers and their physical environments by using demographic variables such as age, gender, duration of membership and the province where the youth center is located. The sample of the study consisted of YC members in Diyarbakır, Kırıkkale, Kocaeli, Trabzon, and Van. A total of 561 volunteers with a mean age of 16-19 (38.5\%) participated in the study. 359 (64\%) of them were women while $202(36 \%)$ were men.

Apart from a personal information form, a scale, designed for the measurement of users' attitudes towards youth centers by the researchers, was employed to collect the research data. The scale was designed using the Leisure Satisfaction Scale (LSS) developed by Beard and Ragheb (1980). The original form of the scale consists of 51 items and 6 sub-factors. The scale used in this study was prepared with 24 items and 6 sub-factors: educational, physiological, relaxing, social, psychological aspects and physical environment. All items were responded to on a 5-point Likert-type scale ranging from '1' (strongly disagree) to '5' (strongly agree). $(1=$ Strongly disagree, $2=$ Disagree, $3=$ neutral, $4=$ Agree, $5=$ Strongly Agree). Karlı et al. (2008) found the validity and reliability coefficient (Cronbach's Alpha coefficient) of the Leisure Satisfaction Scale (LLS) as $\alpha=0.92$. The coefficient of the scale used in this study was $\alpha=$ 0.87. Cronbach's alpha value of 0.70 and above is considered sufficient for reliability in social studies (Özdamar, 2015). Therefore, the new questionnaire developed for this study was highly reliable.

SPSS 21.0 program was used to analyze the data collected in the study. In the analysis of the research data, arithmetic mean, frequency, standard deviation, and percentage values (descriptive statistics) were examined. In order to determine whether parametric analyses should be performed, firstly the distribution obtained from the scale data was examined to check the normality. Kurtosis and skewness values were calculated. The results are given below.

Table 1. Skewness and Kurtosis values of users' Attitudes towards YCs

\begin{tabular}{l|c|c}
\hline Attitudes & Skewness & Kurtosis \\
\hline Relaxation & $-0,404$ & $-0,216$ \\
\hline Socialization & $-0,304$ & 0,253 \\
\hline Psychological effect & $-0,989$ & 1,343 \\
\hline Physiological development & $-0,089$ & $-0,422$ \\
\hline Educational contribution & 0,011 & $-0,192$ \\
\hline Physical environment & $-0,351$ & $-0,532$ \\
\hline
\end{tabular}


The skewness and kurtosis values obtained for the sub-factors of the scale used in this study range between -2 and +2 , which suggests that the research data show normal distribution (George \& Mallery, 2010). Parametric analyses were performed to determine whether the research data differ according to the demographic characteristics of the participants. T-test was used for evaluations between two groups while the one-way ANOVA test and Tukey test were used for more than two groups. The results are presented in Table 1.

\section{Results}

The mean and standard deviation values of sub-factors of the attitudes of the YC members participating in the research are presented in Table 2 .

Table 2. Mean and standard deviation values of users attitudes towards YCs

\begin{tabular}{l|c|c|c}
\hline Attitudes & N & Mean & STD \\
\hline Relaxation & 561 & 3,74 & 1,18 \\
\hline Socialization & 561 & 3,52 & 1,17 \\
\hline Psychological effect & 561 & 3,84 & 1,11 \\
\hline Physiological development & 561 & 3,36 & 1,23 \\
\hline Educational contribution & 561 & 3,55 & 1,21 \\
\hline Physical environment & 561 & 3,79 & 1,22 \\
\hline
\end{tabular}

The subfactor "relaxation" produced a general mean of $\mathrm{x}=3.74 \pm 1.18$, which corresponds to the "agree" range of the 5-point Likert scale. This suggests that the activities and programs carried out by the YCs are organized according to the needs of the users and that they help the users relax and get rid of stress.

The socialization aspect of the scale produced an average of $\mathrm{x}=3.52 \pm 1.17$, which corresponds to the "agree" range of the 5-point Likert scale, suggesting that YC members think the activities, programs, and cultural events contribute to their socialization.

The psychological effect of the programs and activities with a general mean of $\mathrm{x}=3.84 \pm 1.11$ corresponds to the "agree" range of the 5-point Likert scale, suggesting that YCs contribute to the increase of self-confidence in members and have a positive effect on them psychologically.

The YCs' contribution to the physiological development of the users with a general mean of $\mathrm{x}=3.36 \pm 1.23$ corresponds to the "neutral" range of the 5-point Likert scale, suggesting that the members can not say how effective the activities and programs carried out by YCs are on the development of their sporting abilities.

The educational aspect of YCs with a general average of $\mathrm{x}=3.55 \pm 1.21$ corresponds to the "agree" range of the 5-point Likert scale, suggesting that YC users find the activities, programs, employees and youth leaders educationally competent.

The physical environment of the YCs produced a general mean of $\mathrm{x}=3.79 \pm 1.22$, which corresponds to the "agree" range of the 5-point Likert scale, suggesting that YC users find the physical conditions, equipment, and location of the YCs sufficient in general. 
Table 3. One-way ANOVA and Tukey test results showing the evaluation of YC members' attitudes towards centers by age variable

\begin{tabular}{|c|c|c|c|c|c|c|c|}
\hline Attitudes & Age & $\mathbf{N}$ & Mean & STD & $\mathbf{F}$ & $\mathbf{P}$ & Difference \\
\hline \multirow{4}{*}{ Relaxation } & $12-15$ & 131 & 3,36 & 0,84 & \multirow{4}{*}{1,719} & \multirow{4}{*}{0,162} & \\
\hline & 16-19 & 216 & 3,20 & 0,68 & & & \\
\hline & $20-24$ & 172 & 3,32 & 0,64 & & & \\
\hline & $25-28$ & 42 & 3,25 & 0,69 & & & \\
\hline \multirow{4}{*}{ Socialization } & $12-15$ & 131 & 3,43 & 0,79 & \multirow{4}{*}{2,248} & \multirow{4}{*}{0,082} & \\
\hline & $16-19$ & 216 & 3,33 & 0,70 & & & \\
\hline & $20-24$ & 172 & 3,51 & 0,71 & & & \\
\hline & $25-28$ & 42 & 3,51 & 0,83 & & & \\
\hline \multirow{4}{*}{ Psychological Effect } & $12-15$ & 131 & 3,96 & 0,85 & \multirow{4}{*}{4,947} & \multirow{4}{*}{$0,002 *$} & \multirow{4}{*}{$\begin{array}{l}2-1 \\
2-3\end{array}$} \\
\hline & $16-19$ & 216 & 3,67 & 0,78 & & & \\
\hline & $20-24$ & 172 & 3,93 & 0,81 & & & \\
\hline & $25-28$ & 42 & 3,93 & 0,89 & & & \\
\hline \multirow{4}{*}{ Physiological Development } & $12-15$ & 131 & 3,52 & 1,02 & \multirow{4}{*}{3,707} & \multirow{4}{*}{$0,012 *$} & \multirow{4}{*}{$1-2$} \\
\hline & $16-19$ & 216 & 3,20 & 0,93 & & & \\
\hline & $20-24$ & 172 & 3,41 & 0,94 & & & \\
\hline & $25-28$ & 42 & 3,49 & 0,81 & & & \\
\hline \multirow{4}{*}{ Educational Contribution } & $12-15$ & 131 & 2,92 & 0,68 & \multirow{4}{*}{0,606} & \multirow{4}{*}{0,612} & \\
\hline & $16-19$ & 216 & 2,85 & 0,59 & & & \\
\hline & $20-24$ & 172 & 2,92 & 0,64 & & & \\
\hline & $25-28$ & 42 & 2,93 & 0,65 & & & \\
\hline \multirow{4}{*}{ Physical Environment } & $12-15$ & 131 & 2,93 & 0,75 & \multirow{4}{*}{0,439} & \multirow{4}{*}{0,725} & \\
\hline & $16-19$ & 216 & 2,85 & 0,63 & & & \\
\hline & $20-24$ & 171 & 2,89 & 0,69 & & & \\
\hline & $25-28$ & 42 & 2,82 & 0,54 & & & \\
\hline
\end{tabular}

$* \mathrm{p}<0,05$

Table 3 shows the attitudes of the YC members participating in the study obtained from the one-way ANOVA and Tukey tests according to the age variable. The results indicate that psychological impact is significantly lower in 16-19 age group members $(x=3.67 \pm 0.78)$ than $12-15$ group members $(x=3.96 \pm 0.85)$ and $20-24$ age group members $(x=$ $3.93 \pm 0.81)(\mathrm{p}<0.05)$. The 12-15 age group's attitude levels towards the physiological development subfactor $(\mathrm{x}=3.52$ $\pm 1.02)$ were significantly higher than $16-19$ age group members $(x=3.20 \pm 0.93)(p<0,05)$. 
Table 4. One-way ANOVA and Tukey test results showing the evaluation of YC members' attitudes towards by membership period variable.

\begin{tabular}{|c|c|c|c|c|c|c|c|}
\hline Attitudes & $\begin{array}{c}\text { Membership } \\
\text { Period }\end{array}$ & $\mathbf{N}$ & Mean & STD & $\mathbf{F}$ & $\mathbf{P}$ & Difference \\
\hline \multirow{4}{*}{ Relaxation } & 1-6 months & 290 & 3,70 & 0,80 & \multirow{4}{*}{1,430} & \multirow{4}{*}{0,233} & \\
\hline & 7-12 months & 81 & 3,74 & 0,74 & & & \\
\hline & $1-2$ years & 104 & 3,88 & 0,75 & & & \\
\hline & Over 2 years & 86 & 3,68 & 0,84 & & & \\
\hline \multirow{4}{*}{ Socialization } & 1-6 months & 290 & 3,45 & 0,67 & \multirow{4}{*}{2,770} & \multirow{4}{*}{$0,041 *$} & \multirow{4}{*}{$1-3$} \\
\hline & 7-12 months & 81 & 3,53 & 0,65 & & & \\
\hline & $1-2$ years & 104 & 3,68 & 0,72 & & & \\
\hline & over2 years & 86 & 3,54 & 0,73 & & & \\
\hline \multirow{4}{*}{ Psychological Effect } & 1-6 months & 290 & 3,80 & 0,87 & \multirow{4}{*}{0,649} & \multirow{4}{*}{0,584} & \\
\hline & 7-12 months & 81 & 3,85 & 0,67 & & & \\
\hline & 1-2 years & 104 & 3,93 & 0,80 & & & \\
\hline & over2 years & 86 & 3,83 & 0,85 & & & \\
\hline \multirow{4}{*}{ Physiological Development } & 1-6 months & 290 & 3,19 & 0,97 & \multirow{4}{*}{8,513} & \multirow{4}{*}{$0,000 *$} & \multirow{4}{*}{$\begin{array}{l}1-3 \\
1-4\end{array}$} \\
\hline & 7-12 months & 81 & 3,33 & 0,82 & & & \\
\hline & $1-2$ years & 104 & 3,62 & 0,96 & & & \\
\hline & over2 years & 86 & 3,65 & 0,86 & & & \\
\hline \multirow{4}{*}{ Educational Contribution } & 1-6 months & 290 & 3,53 & 0,65 & \multirow{4}{*}{1,023} & \multirow{4}{*}{0,382} & \\
\hline & 7-12 months & 81 & 3,49 & 0,61 & & & \\
\hline & $1-2$ years & 104 & 3,58 & 0,69 & & & \\
\hline & over2 years & 86 & 3,65 & 0,75 & & & \\
\hline \multirow{4}{*}{ Physical Environment } & 1-6 months & 289 & 3,79 & 0,74 & \multirow{4}{*}{2,102} & \multirow{4}{*}{0,099} & \\
\hline & 7-12 months & 81 & 3,62 & 0,79 & & & \\
\hline & $1-2$ years & 104 & 3,84 & 0,81 & & & \\
\hline & over 2 years & 86 & 3,90 & 0,80 & & & \\
\hline
\end{tabular}

$* p<0,05$

The attitudes of the users towards the youth centers according to the one-way ANOVA and Tukey tests for the membership period variable are presented in Table 4. The results of the analysis show that the attitude scores of the users with membership period of $1-2$ years $(x=3.68 \pm 0.72)$ were significantly higher for the socialization sub-factor than the 1-6 months group $(x=3.45 \pm 0.67)(\mathrm{p}<0,05)$.

The attitude levels of the members whose membership periods were 1-6 months $(x=3.19 \pm 0.97)$ for physiological development subfactor were significantly lower than those with a membership of 1-2 years $(\mathrm{x}=3.62 \pm 0.96)$ and more than 2 years $(x=3,65 \pm 0,86)(p<0,05)$. 
Table 5. One-way ANOVA and Tukey test results showing the assessment of users' attitudes towards centers by province variable

\begin{tabular}{|c|c|c|c|c|c|c|c|}
\hline Attitudes & Provinces & $\mathbf{N}$ & Mean & STD & $\mathbf{F}$ & $\mathbf{P}$ & Difference \\
\hline \multirow{5}{*}{ Relaxation } & Kırıkkale & 131 & 3,89 & 0,76 & \multirow{5}{*}{4,097} & \multirow{5}{*}{$0,003 *$} & \multirow{5}{*}{$\begin{array}{c}1-3 \\
2-3\end{array}$} \\
\hline & Kocaeli & 149 & 3,82 & 0,72 & & & \\
\hline & Van & 116 & 3,54 & 0,91 & & & \\
\hline & Trabzon & 91 & 3,61 & 0,73 & & & \\
\hline & Diyarbakır & 74 & 3,77 & 0,79 & & & \\
\hline \multirow{5}{*}{ Socialization } & Kirıkkale & 131 & 3,66 & 0,66 & \multirow{5}{*}{2,539} & \multirow{5}{*}{$0,039 *$} & \multirow{5}{*}{$1-4$} \\
\hline & Kocaeli & 149 & 3,50 & 0,64 & & & \\
\hline & Van & 116 & 3,45 & 0,83 & & & \\
\hline & Trabzon & 91 & 3,40 & 0,52 & & & \\
\hline & Diyarbakır & 74 & 3,56 & 0,74 & & & \\
\hline \multirow{5}{*}{ Psychological Effect } & Kırıkkale & 131 & 3,98 & 0,72 & \multirow{5}{*}{1,350} & \multirow{5}{*}{0,250} & \\
\hline & Kocaeli & 149 & 3,78 & 0,84 & & & \\
\hline & Van & 116 & 3,78 & 0,97 & & & \\
\hline & Trabzon & 91 & 3,80 & 0,74 & & & \\
\hline & Diyarbakır & 74 & 3,83 & 0,80 & & & \\
\hline \multirow{5}{*}{ Physiological Development } & Kırıkkale & 131 & 3,62 & 0,91 & \multirow{5}{*}{6,336} & \multirow{5}{*}{$0,000^{*}$} & \multirow{5}{*}{$\begin{array}{l}1-2 \\
1-4\end{array}$} \\
\hline & Kocaeli & 149 & 3,10 & 0,94 & & & \\
\hline & Van & 116 & 3,43 & 0,99 & & & \\
\hline & Trabzon & 91 & 3,24 & 0,93 & & & \\
\hline & Diyarbakır & 74 & 3,47 & 0,88 & & & \\
\hline \multirow{5}{*}{ Educational Contribution } & Kırıkkale & 131 & 3,55 & 0,62 & \multirow{5}{*}{6,435} & \multirow{5}{*}{$0,000^{*}$} & \multirow{5}{*}{$\begin{array}{l}2-3 \\
5-3\end{array}$} \\
\hline & Kocaeli & 149 & 3,72 & 0,66 & & & \\
\hline & Van & 116 & 3,33 & 0,74 & & & \\
\hline & Trabzon & 91 & 3,49 & 0,55 & & & \\
\hline & Diyarbakır & 74 & 3,65 & 0,69 & & & \\
\hline \multirow{5}{*}{ Physical Environment } & Kırıkkale & 130 & 4,03 & 0,75 & \multirow{5}{*}{7,805} & \multirow{5}{*}{$0,000^{*}$} & \multirow{5}{*}{$\begin{array}{l}1-2 \\
1-3 \\
1-4 \\
5-3 \\
5-4\end{array}$} \\
\hline & Kocaeli & 149 & 3,74 & 0,75 & & & \\
\hline & Van & 116 & 3,65 & 0,87 & & & \\
\hline & \begin{tabular}{|l|} 
Trabzon \\
\end{tabular} & 91 & 3,56 & 0,64 & & & \\
\hline & Diyarbakır & 74 & 3,98 & 0,72 & & & \\
\hline
\end{tabular}

The attitudes of the users towards the youth centers for the province variable according to the one-way ANOVA and Tukey tests analysis are presented in Table 5:

Relaxation: the users in Kırıkkale and Kocaeli showed significantly higher attitude levels than those in Van;

Socialization: the users in Kurıkkale had significantly higher scores than those in Trabzon;

Physiological development: the users in Kurıkkale had significantly higher scores than those in Kocaeli and Trabzon;

Educational contribution: the users in Kocaeli and Diyarbakır had significantly higher attitude scores than those in Van; Physical environment: the users in Kırıkale, Diyarbakır, and Kocaeli showed significantly higher attitude levels than those in Van and Trabzon $(\mathrm{p}<0,05)$. 
Table 6. T-test results showing users' attitudes towards youth centers by sex.

\begin{tabular}{|c|c|c|c|c|c|c|}
\hline Attitudes & Sex & $\mathbf{N}$ & Mean & Std & $\mathbf{T}$ & $\mathbf{P}$ \\
\hline \multirow{2}{*}{ Relaxation } & $\mathrm{F}$ & 359 & 3,26 & 0,71 & \multirow{2}{*}{$-0,739$} & \multirow{2}{*}{0,460} \\
\hline & $\mathrm{M}$ & 202 & 3,31 & 0,72 & & \\
\hline \multirow{2}{*}{ Socialization } & $\mathrm{F}$ & 359 & 3,38 & 0,71 & \multirow{2}{*}{$-1,880$} & \multirow{2}{*}{0,061} \\
\hline & $\mathrm{M}$ & 202 & 3,50 & 0,78 & & \\
\hline \multirow{2}{*}{$\begin{array}{l}\text { Psychological } \\
\text { Effect }\end{array}$} & $\mathrm{F}$ & 359 & 3,86 & 0,83 & \multirow{2}{*}{0,834} & \multirow{2}{*}{0,405} \\
\hline & $\mathrm{M}$ & 202 & 3,80 & 0,82 & & \\
\hline \multirow{2}{*}{$\begin{array}{l}\text { Physiological } \\
\text { Development }\end{array}$} & $\mathrm{F}$ & 359 & 3,27 & 0,93 & \multirow{2}{*}{$-3,018$} & \multirow{2}{*}{$0,003 *$} \\
\hline & $\mathrm{M}$ & 202 & 3,52 & 0,98 & & \\
\hline \multirow{2}{*}{$\begin{array}{l}\text { Educational } \\
\text { Contribution }\end{array}$} & $\mathrm{F}$ & 359 & 2,85 & 0,62 & \multirow{2}{*}{$-1,889$} & \multirow{2}{*}{0,059} \\
\hline & $\mathrm{M}$ & 202 & 2,96 & 0,65 & & \\
\hline \multirow{2}{*}{$\begin{array}{l}\text { Physical } \\
\text { Environment }\end{array}$} & $\mathrm{F}$ & 358 & 2,85 & 0,66 & \multirow{2}{*}{$-1,138$} & \multirow{2}{*}{0,256} \\
\hline & $\mathrm{M}$ & 202 & 2,92 & 0,69 & & \\
\hline
\end{tabular}

The attitudes of the users towards youth centers according to the T-test analysis by sex variable are presented in Table 6 . Male users had more positive attitudes than female members for the physiological development sub-factor $(\mathrm{p}<0.05)$. It means that the male members of YCs find the youth centers more adequate in terms of physiological needs. The results also reveal that more men would rather go to youth centers for sports activities.

\section{Discussion}

The mean and standard deviation results reveal that the psychological effect sub-factor showed the highest average. It means that the users have a very positive attitude towards YCs about self-confidence gaining, skill acquisition, stress-relieving, the feeling of comfort and safety, and free choice of activities. In a study conducted by Yaman et al. (2016), which produced similar results to the ones obtained from our research, it was found that the highest mean was in the relaxation aspect while the lowest mean was in physiological development. The same study also shows that the level of leisure satisfaction of individuals participating in youth center activities is high. Sönmezoğlu, Polat and Aycan (2014) conducted a study to determine the leisure satisfaction levels of the members of youth centers according to some demographic variables. According to the findings of this study, the satisfaction level of the participants was found to be highest in the relaxation sub-factor and the lowest in the physiological development dimension. Baş (2016) found that the activities carried out in YCs, in general, had positive effects on the socialization, personal development and education of the youth. Pisarczyk (1993) stated that the leisure activities offered in the YCs can only achieve success if they meet the leisure needs of young visitors by entertaining them and contributing to their personal development.

T-test analysis conducted by the sex variable revealed that there was no significant difference in the attitudes of male and female participants in general. However, it was determined that male participants were more involved in sports activities than women. Karlı et al. (2008b) stated that the satisfaction level of women was higher in the relaxation aspect while the satisfaction level of men was higher in the physiological dimension. Shin and You (2013) conducted a study on activity type and leisure satisfaction and found that men and women had positive satisfaction levels for sporting activities. Another study (Yaman et al., 2016) revealed that the leisure satisfaction scores of the participants differed only in the education and relaxation subscales, where women had higher satisfaction levels than men. Our study, in fact, produced different results in this context. Another study (Sönmezoğlu et al., 2014) showed that women's leisure satisfaction levels were higher than men in the psychological, education and relaxation subscales.

The results of the ANOVA and Tukey tests conducted to see whether there is a significant difference between the provinces in which the research was conducted revealed that attitudes towards Kurkkale and Kocaeli YCs in terms of relaxation, socialization, physiological, development, educational contribution, and physical environment were found to be more positive than Van and Trabzon provinces. The reason why the attitude levels in Kirıkale are higher might be that the youth center where the survey was conducted in Kırıkkale province is located in Yahşihan district, where Kırıkkale University is also located. The majority of its members are university students and they participate in youth center activities more consciously. In addition, factors such as physical environments of YCs, differences in programs 
and activities carried out by provinces, the behavior of employees or characteristics of other member participants may cause such differences.

Analyses by age revealed that the attitude levels of the users of 16-19 years of age were lower in the psychological subscale than the attitude scores of 12-15 and 20-24 age groups. This might be due to the fact that the stress and anxiety levels of the 16-19 age group are higher than the other groups because of the university exam preparations.

Analyses by membership period revealed that the attitudes of young people with longer membership periods were more positive in social and physiological subscales. This might be due to the fact that continuing youth centers for a longer period of time strengthens the sense of belonging in the youth. Bilgen (2014), who studied the impact of programs conducted by youth centers on the users, stated that the young people participating in the programs in the Yenimahalle Youth Center in Ankara showed a significant difference in communication and social skills depending on the duration of absenteeism and sex. In another study, statistically significant positive relationships were found between membership periods, the frequency of attendance and the leisure satisfaction levels (Sönmezoğlu et al., 2014).

The results of this study indicate that youth centers contribute to the educational, social, psychological and physiological development of young people in general, help them to get away from stress and affect their academic success positively. Youth is a process in which physical, mental and emotional development is experienced in a fast, stressful and complex way. During this process, young people's quest for identity intensifies. They pass through various positive and negative conditions and experience adaptation problems to new environments with new friends. They are also expected to be successful academically. The major duties and responsibilities of youth centers are to help the youth cope with their problems during this harsh process by organizing programs and creating opportunities for leisure activities to contribute to their academic success, to the development of their physical abilities, and to their socialization, A healthy youth process will lead to success and improvement of life quality.

To conclude, youth centers could play an important role in the betterment of the society by conducting rich activities and programs in accordance with the spirit of the age and the needs of young people with professional employees and trainers, adequate physical infrastructure and equipment, and convenient transportation facilities.

\section{Acknowledgments}

We would like to thank Diyarbakır, Kırıkkale, Kocaeli, Trabzon and Van Youth Centers (YC) of the Ministry of Youth and Sports (MYS) and their users. This study has been produced from the master's thesis titled "Youth Center Activities and Examination of Members Levels of use of Youth Centers" Master's Degree Student, Kırıkkale University, Graduate School of Health Sciences, Department of Physical Education and Sports.

\section{References}

AA. (2019). Turkey's young population ratio is ahead of Europe. Anadolu Ajansı. Retrieved from https://www.aa.com.tr/tr/turkiye/turkiye-genc-nufusta-avrupayi-solladi/1480438

Baş, H. (2016). Local government's youth services: Example of Esenler youth center in Istanbul. Unpublished Master Degree, Istanbul University, Institute of Social Sciences, Istanbul.

Beard, J. G., \& Ragheb, M. G. (1980). Measuring leisure satisfaction. Journal of Leisure Research, 12(1), 20-33. https://doi.org/10.1080/00222216.1980.11969416

Bilgen, H. (2014). An investigation on social and communication skills of youth attending courses conducted in the youth center in terms of certain variables (The sample of Yenimahalle in Ankara province), Master Degree, Gazi University, Ankara.

Broughton, K., \& Beggs, B. A. (2006). Leisure satisfaction of older adults. Activities, Adaptation \& Aging, 31(1), 1-18. https://doi.org/10.1300/J016v31n01_01

Duden. (2016). Youth center. Retrieved from http://www.duden.de

Dumazedier, J. (1974). Sociologie empirique dulloisir. Paries: Edition dul Seuil, 1974.

George, D., \& Mallery, M. (2010). SPSS for windows step by step: a simple guide and reference. Boston: Pearson.

Güçlü, M. (2013). The significance and importance of leisure time activities in youth period. Gençlik Araştırmaları Dergisi, l(1), 158-169.

Heaven, C., \& Tubridy, M. (2003). Global youth culture and youth identity. Highly affected, rarely considered. The International Youth Parliament Commission's report on the impacts of globalisation on young people, 149-160.

Karabulut, E. O., \& Pulur, A. (2011). A comparison of the problem solving skills of the representatives of juveniles from youth centers by different variables. Spormetre the Journal of Physical Education and Sport Sciences, 9(2), 71-80. 
Karlı, Ü., Polat, E., Üzüm, H., \& Koçak, S. (2008b.) The leisure satisfaction levels of university student. $10^{\text {th }}$ International sport sciences congress, October 23-25, Bolu/Turkey. Retrieved from http://www.sporbilim.com/dosyalar/Oral\%28sozel\%29_Sunumlar.pdf

Karlı, Ü., Polat, E., Yılmaz, B., \& Koçak, S. (2008). Reliability and validity study of leisure satisfaction scale (LSS-Long Version). Hacettepe Jornal of Sport Sciences 2008, 19(2), 80-91.

MYS. (2013). National youth and sports policy document. Ministry of youth and sports in Turkey. Retrieved from https://www.gsb.gov.tr/public/edit/files/Mevzuat/ulusal_genclik_ve_spor_politikasi.pdf

MYS. (2016). Ministry of youth and sports 2015 administration annual report. Ministry of youth and sports in Turkey. Retrieved from http://www.gsb.gov.tr/public/edit/files/strateji/2015_yili_faaliyet_raporu.pdf/

Özdamar, K. (2015). Structural equation modeling for scale and test development. Ankara: Nisan Publication.

Pisarczyk, S. (1993). Youth centers in Germany-cultural houses in Poland. A comparative educational comparison. Freizeitpädagogik, 15(3), 227-235.

Shin, K., \& You, S. 2013. Leisure type, leisure satisfaction and adolescents' psychological wellbeing. Journal of Pacific Rim Psychology, 7(2), 53-62. https://doi.org/10.1017/prp.2013.6

Sönmezoğlu, U., Polat, E., \& Aycan, A. (2014). Youth center members and according to some variables levels of leisure satisfaction. International Journal of Sport Culture and Science, 2(Special Issue 1), 219-229. https://doi.org/10.14486/IJSCS91

TDK. (2016). Youth. Turkish language society inc. Retrieved from www.tdk.gov.tr

UNESCO. (2014). Youth. Retrieved from https://unevoc.unesco.org/go.php?q=TVETipedia+Glossary+A-Z\&id=9

UNICEF. (2011). The state of the world's children 2011. Adolescence an age of opportunity Asia-Pacific interagency group on youth. Investing in youth policy. UNICEF publications.

Yaman, B., Akgül, B. M., Karaman, M., Ayyıldız, T., \& Karaküçük, S. (2016). Examination of leisure satisfaction levels of individuals participating in youth center activities. Niğde University Journal of Physical Education and Sport Sciences, 10(3), 474-487.

Yörükoğlu, A. (2007). Youth. 13th Edn., İstanbul: Özgür Publication.

\section{Copyrights}

Copyright for this article is retained by the author(s), with first publication rights granted to the journal.

This is an open-access article distributed under the terms and conditions of the Creative Commons Attribution license which permits unrestricted use, distribution, and reproduction in any medium, provided the original work is properly cited. 